\title{
Law Games - Role Play And Simulation In Teaching Legal Application And Practical Skills: A Case Study
}

\author{
Edward Phillips \\ University of Greenwich, Department of Law \& Criminology
}

\section{Introduction}

The binary divide between the academic and the vocational-professional stages of legal education present special problems for law teachers who wish to achieve the dual goals of encouraging a deeper engagement among law students as well as to contextualise their classroom experiences. Achieving these goals is one reliable method of ensuring that deep learning, as opposed to surface learning, takes place (Hussey and Smith, 2010). The problem may be put in succinct form: how do law teachers introduce a healthy dose of reality to balance out the academic-conceptual discussion that takes place in lectures and seminars? To use an obvious example, an in-depth discussion of the legal technicalities relating to the principles of negligence must, perforce, remain 'merely academic' without the addition of the crucial role of insurance in the mitigation and mediation of the payment of damages. A simulated/role-play exercise, involving perhaps, the negligent driver of a motor vehicle, increases the possibility of student understanding and engagement, with the crucial notion that such claims are, in fact, 'run' by insurance companies; those students who are drivers will understand this point immediately while it is not too difficult to explain this point to non-drivers.

The absence of a clinical element in the undergraduate teaching of law students perpetuated since the various reforms of legal education in the 1970 s and 1980s, has too often encouraged an unfortunate separation between the law school and the vocational/professional stages of legal education, and on into the world of the working practitioner. This is in total contrast to the pedagogic methods applicable in the teaching of a range of other disciplines. From medical education to drama and architecture, it is taken for granted that education involves simulation, role-play and experiential (or clinical) learning.

Conversely, legal education appears to offer the ideal environment for the use of simulated learning mechanisms. As Twinning puts it, "law as a discipline is constantly fed with practical problems and materials from the 'real world': actual rather than hypothetical cases; proposals for legislative reform; and social problems from domestic violence and crime to world peace and environmental survival", (Twinning, 1994).

Crucially, simulation serves at least one essential function: it assists in overcoming some, at least, of the psychological barriers to deep learning. While it would be going too far to claim that simulation, in its various forms, is the ultimate panacea, it remains true that this is a pedagogical method that is too rarely utilised by law teachers whilst it is also a method that has the potential to elevate and re-energise the classroom 
experience (Moizer, Lean, Towler and Abbey, 2006). Finally, simulated learning strategies mediate the significant transition from university to work place.

\section{Problem solving, role play and simulations}

There are a diversity of role play models, at least one of which is in common use in law schools: problemsolving. Typically, this involves presenting the student with a given set of facts, followed by the instruction, 'advise the claimant (defendant/prosecution)'. The problems with the 'problem question', however, are manifold. First, it is constrained by the set of facts which, perforce, has been set by the teacher and within which the student-adviser is forced to work. Second, in the 'real world' of the practising professional, facts do not present themselves ready-packaged; it is the task of the legal professional to obtain the facts, to sift out what is relevant from the chaff and to manage facts. The task is as much one of fact-management as fact-solving. Finally, the stage-managed set of facts within which problem-solving occurs stifles creativity and the impulse to work 'outside the box'. The typical response to the lateral-thinking student is, 'stick to the facts which have been provided'. And yet, it is precisely this form of thinking that higher education (in law or in any other discipline) should be focused on encouraging.

Role play in the form of problem-solving does offer the advantage of being convenient, tried-and-tested and economical in terms of time and resources. Moreover, taken together with the essay question, it has become the standard form of coursework and examination assessment. This is perhaps the primary reason both for its over-use as well as for the lack of attention to other forms of role play. At least three possibilities may be noted here, all of which have been used with great success by law academics at the University of Greenwich. These are (a) moots, (b) client interviewing and counselling, and (c) mock trials.

A detailed study of these techniques is beyond the scope of the present paper. However, it is worth noting that the common feature of all three is that they involve role play in a form which is open-ended. This is unlike problem-solving, where the desired end is designed into the problem. To re-iterate the point, these simulations may produce conclusions which may surprise. In much the same way that a verdict of guilt may surprise those who have followed the media reporting of a criminal trial, so too the teacher and even the student may be surprised by the outcomes reached in these simulation exercises. But, then, this is in the very nature - and the value - of these exercises.

Nonetheless, the fact that simulations are time- and resource-greedy cannot be overlooked; this has to be factored into the pedagogic decision to use them and the careful planning that is required. The challenge (and the rewards) for the law teacher are clear, "the driving force for diversity and innovation is the common goal of improving the quality of student learning and achievement." (Phillips, Clarke, Laycock and Crofts, 2010).

\section{The Law of Evidence: a case study}

The Law of Evidence is an optional course, usually offered in the final year and taken by those students who have chosen a career pathway leading to professional qualification. It is, in many crucial aspects, the paradigm undergraduate course that bridges the divide between the academic and the practical/ vocational, thus providing the ideal opportunity for simulation-based learning. Moreover, understanding the legal principles pertaining to admissibility and proof constitute only a small part of this subject. The central subject matter of the Law of Evidence is its emphasis on two matters of concern (Twinning, 2006). The first is the focus on proof and fact-finding. Questions of how to prove and fact determination (or, indeed, fact scepticism) are the essential concerns of the Law of Evidence. Secondly, the Law of Evidence is the ideal vehicle for the teaching of a range of inter-disciplinary skills, primarily relating to logic and inferential deduction. Both of these lend themselves seamlessly to simulation-based teaching and learning. 


\section{Teaching fact determination, fact evaluation and legal application}

The teaching and assessment of the Law of Evidence at Greenwich has been radically overhauled to incorporate simulations as the main teaching mechanism. Teaching on the course revolves around a case study, culminating in a civil claim as well as criminal proceedings. The case study is used to illustrate the legal principles, the manner of their practical application, the basis for criticism and evaluation as well as a range of assessment exercises (both formative and summative). The full range of simulations is employed, including: interviewing, counselling and advising, negotiation, research and opinion writing and advocacy. The exercises take place at the appropriate point in the syllabus over the academic year. All exercises are then written up in a final portfolio. Crucially, therefore, the simulations are designed not only to be a teaching mechanism but also as a component of the assessment in the course. While there is a final year examination, along fairly traditional lines, the portfolio of simulation assessments accounts for $40 \%$ of the overall grade for the course.

The simulation exercises are designed in such a manner so as to pitch the challenge to just beyond and above what the students think they are capable of achieving. Simulations and role play thus move students outside their comfort zone into a position where (a) deep learning takes place, and (b) students take responsibility for their own learning. Each exercise is prefaced with adequate briefing, and where necessary and appropriate, with a preceding formative exercise. Although some simulations require students to work on their own, some also require peer-group activity; sometimes as part of a pair, as part of a larger group or as a whole-class exercise. On some occasions, peer-group assessment is also used (but only for formative assessment). Where appropriate, students may choose their role or, in other instances, be assigned to a particular role by the teacher.

In all cases, the exercise will be written up, as a brief report, by the student concerned.

The case study involves (a) a civil action for medical negligence, and (b) a criminal prosecution for gross negligence manslaughter. The various simulation exercises include the following:

Client interviewing to determine the facts surrounding the claim/prosecution

Interviewing witnesses, drafting witness statements and assessing the legal efficacy of witness statements

Assessing the propriety of police interrogation of the defendant, through transcripts and the police custody record

Assessing the reports produced by the forensic experts

The examination and cross-examination of the forensic experts

Assisting the trial judge in the preparation of the essential directions to the jury

The preparation of appeal documents.

Additional exercises are added throughout the course, as and when necessary. For instance, applications may be made for directions (including special measures directions in relation to the examination of any 'vulnerable' witnesses) or in relation to admissibility of hearsay statements.

\section{Conclusion}

Simulation-based teaching and learning offer a number of pedagogic rewards. These include the fact that it is student-centred rather than teacher-centred; it identifies gaps not discernible in conventional learning; 
it focuses on students' real knowledge and skills; it integrates reality and context with academic learning (including interviewing skills and practical advice-giving, as well as the ability to deal with the unexpected); and it effectively engages the student in the learning process. Moreover, since simulated learning almost always involves co-operative or peer-focussed activity, it nurtures a range of 'soft' skills (such as organisation and team-working, tactical/strategic selection) and the whole range of communication skills (language, articulation and presentation). Finally, it allows for student experimentation, something often ignored in legal education.

The skills deficit amongst law students causes a problematic transition from school to law school. Role play and simulations, by their very nature, allow the creative development of these skills. This is especially the case with regard to language, articulation, critical thinking innovation and other 'soft skills'. In short, all the elements that constitute professionalism and the attributes of 'graduate-ness'. Just as important, the student is better placed to successfully negotiate the onward transition from university to vocational /professional education and thence on to the work-place. Crucially, these techniques of teaching and assessment nurture an holistic approach to understanding what law is for and what law does.

\section{References}

Hussey, T., and Smith, P. (2010). Transitions in Higher Education. Innovations in Education and Teaching International, 47 (2), pp. 155-164.

Moizer, J., Lean, M., Towler, M., and Abbey, C. (2006). Simulations and Games: Overcoming the Barriers to their use in Higher Education. Active Learning in Higher Education, 10 (3), pp. 207-224.

Phillips, E., Clarke, S., Laycock, A., and Crofts, S. (2010) Exceeding the Boundaries of Formulaic Assessment. The Law Teacher, 44 (3), pp. 334-364.

Twinning, W. (1994) Blackstone's Tower: The English Law School. London: Sweet and Maxwell.

Twinning, W. (2006) Re-Thinking Evidence: Exploratory Essays. Cambridge: Cambridge University Press. 